Araştırma Makalesi / Research Article

Geliş tarihi / Received: 20-09-2020

Kabul tarihi / Accepted: 11-12-2020

Fungal Fermantasyonu ile Elma ve Domates Posasının Besleme Değerinin Artırılması

\author{
Ramazan TOSUN ${ }^{1}$, Sulhattin YAŞAR ${ }^{2}$
}

ÖZET: Bu çalışmada biyoreaktör kullanılarak Aspergillus niger (A. niger) ile elma ve domates posasının katıfaz fermantasyonu yöntemiyle besleme değerinin artırılması ve antibesinsel faktörlerin azaltılması ve ayrıca bazı biyomoleküllerce zenginleştirek fonksiyonel yem katkı maddesi olarak kullanılması amaçlanmıştır. Elma ve domates posaları A. niger ile optimum nem (\%91), sicaklık $\left(28^{\circ} \mathrm{C}\right)$ ve $\mathrm{pH}(4-4.5)$ değerlerinde 72 saat fermente edilmiştir. Her iki fermantasyonun 0, 24, 48 ve 72. saatlerinde steril koşullarda bağımsız olarak 3 örnekleme yapılmıştır. Örnekler kurutulduktan sonra besin maddeleri, antibesinsel maddeler ve organik asit içerikleri tespit edilmiştir. Elma posasının A. niger ile fermantasyonunda ham kül içeriği artmıştır. Her iki posanın ham yağ ve toplam redükte şeker içeriği $A$. niger fermantasyonu ile artmıştır. Her iki posanın da A. niger ile fermentasyonu sonucu ham selüloz, asit deterjan fiber, nötr deterjan fiber ve lignin içeriklerinin önemli düzeyde azaldığı tespit edilmiştir. Elma ve domates posasının A. niger ile fermantasyonunda laktik asit ve toplam organik asit içeriği önemli derecede artmıştır. Tanin içeriği fermantasyona bağlı olarak azalırken pektin içeriği fermente domates posasında azalmış, ancak fermente elma posasında artmıştır. Sonuç olarak elde edilen fermente son ürünün hayvan beslemede özellikle de kanatlı hayvanların beslenmesinde organik asitlerce zengin yem katkı maddesi olarak kullanılma olanağı artmıştır, ancak elde edilen bu sonuçların hayvan denemesi ile de desteklenmesine ihtiyaç olduğu sonucuna varılmıştır.

Anahtar Kelimeler: Aspergillus niger, domates posas1, elma posası, kat1-faz fermantasyon, yem katk1 maddesi

\title{
Increasing the Nutrition Qualities of Apple and Tomato Pomace Via Fungal Fermentation
}

\begin{abstract}
This study aimed to improve nutritional qualities and to reduce antinutritional factors of apple and tomato pomace by solid-state fermentation using Aspergillus niger (A. niger) in a bioreactor as well as to enrich with some biomolecules to be used as feed additive. Fermentation with A. niger was carried out at optimised values of moisture (91\%), temperature $\left(28{ }^{\circ} \mathrm{C}\right)$ and $\mathrm{pH}$ (4-4.5) for 72 hours. Three independent samples were taken at $0,24,48$ and $72 \mathrm{~h}$ in sterile conditions. Dried samples were then analysed for the contents of nutrients, antinutrional and organic acids. Crude ash content increased in fermented apple pomace with A. niger. In both fermented materials the contents of crude fiber, acid detergent fiber, neutral detergent fiber and lignin were significantly decreased. Lactic acid and total organic acid content increased significantly in fermented apple and tomato pomace by A. niger. However, the tannin contents decreased in both fermented substrates, but peçtin content was decreased in fermented tomato pomace and there was an increased pectin content in fermented apple pomace. In conclusion, Aspergillus niger fermentation lead to significant enrichment of apple and tomate pomace with organic acids which may exhibit an important feed additive, but further animal trials are on the way to test beneficial in vivo effect.
\end{abstract}

Keywords: Aspergillus niger, tomato pomace, apple pomace, solid-state fermentation, feed additives

Ramazan TOSUN (Orcid ID: 0000-0002-8209-6362), Iğdır Üniversitesi, Ziraat Fakültesi, Zootekni Bölümü, Iğdır, Türkiye

${ }^{2}$ Sulhattin YAŞAR (Orcid ID: 0000-0001-9334-1303), Karamanoğlu Mehmetbey Üniversitesi, Mühendislik Fakültesi, Gıda Mühendisliği Bölümü, Karaman, Türkiye

*Sorumlu Yazar/Corresponding Author: Ramazan TOSUN, e-mail: ramazantosun68@gmail.com

Bu çalışma Ramazan TOSUN'un Yüksek Lisans tezinin bir bölümündür. 


\section{GíRİş}

Hayvancılık işletmelerinde karlılığı etkileyen en önemli etken ucuz ve kaliteli yem kaynağı bulabilmektir. İşletme giderlerinin yaklaşık \%60-70'ini yem giderleri oluşturmakta ve işletmenin karlılığında önemi büyüktür. Son yıllarda yaşanan yem fiyatlarının istikrarsızlığı, miktar ve kalite bakımından yemlerin yetersizliği nedeniyle araştırmacıları alternatif yem kaynağı araştırmaya ve bulmaya yönlendirmiştir (Vasta ve ark., 2008). Bu bağlamda hayvancılıkta alternatif yem kaynaklarının işletme karlılığını pozitif yönde etkilediği ve hayvancılıkta alternatif yem kaynağının önemini ortaya koyan çalışmalar da mevcuttur (Duru ve Kaya, 2015). Dünya' da ve ülkemizde tarım ve gıda ürünlerini işleyen fabrikalar faaliyet göstermekte ve üretim sonrası işlenen ürün miktarının en az \%30'u oranında çeşitli sebze ve meyvelerin kabuk, yaprak ve sap gibi alternatif yem özelliğine sahip bazı yan ürünler oluşmaktadır (AboSiada ve ark., 2017). Genellikle posa olarak ortaya çıkan bu yan ürünler ülkemizde ruminant ve kanatlı hayvanların beslenmesinde alternatif yem kaynağı olarak kullanılmaktadır. Domates ve elma posaları tarımsal sanayinin geliştiği bölgelerde ayrı bir öneme sahip alternatif yem kaynağıdır. $\mathrm{Bu}$ posalar, taze ve kuru olarak tüketilebileceği gibi silolanarak da depolanabilir. Dünya'da ve Türkiye'de domates ve elma posaları ruminant hayvanların beslenmesinde taze, silolanmış veya kurutulmuş olarak, kanatlı hayvanların beslenmesinde ise kurutulmuş olarak hayvanlara yedirilmektedir (Yannakopoulos ve ark., 1992; Yıldız ve ark., 1998; Abdollahzadeh ve ark., 2010). Fakat bu posalar mevsimlik üretilmeleri nedeniyle kısa zamanda çok fazla ürün elde edilmesi, yüksek oranda nem içeriğinden dolayı muhafaza edilme zorluğu ve yapay kurutma işleminin ekstra ekonomik yük oluşturması nedeniyle hayvancılıkta kullanımını sınırlamaktadır (Weiss ve ark., 1997). Diğer taraftan bu posalar tanin ve pektin gibi antibesinsel faktörler içermektedir (King ve Zeidler, 2004; Al-Betawi, 2005; Wadhwa ve Bakshi, 2016). Ruminant hayvanlar rumen fermantasyonu sayesinde bu antibesinsel faktörlerden etkilenmese de kanatlılar için önemli bir sorun oluşturmaktadır. Bu ve benzeri sebeplerden dolayı yemlerin daha yarayışı hale getirilmesi ve besleme değerinin artırılması amacıyla son yıllarda katı-faz fermantasyondan (KFF) yararlanılmaktadır (Joshi ve Devender, 2006; Mukherjee ve ark., 2016). KFF nemin olmadığı veya çok az bulunduğu, suda az veya hiç çözünmeyen katı substratların bulunduğu ortamda mikroorganizmaların kendi doğal ortamındakine benzer şekilde çoğalması ve faaliyet göstermesi olarak tanımlanabilir (Pandey, 2003). KFF ile fungal saf kültürler kullanılarak gerçekleştirilen fermantasyonlarda özellikle tarımsal yan ürünlerin besin madde içeriklerinin zenginleştirildiği ve antibesinsel faktör içeriklerinin (ham selüloz dahil) ciddi bir şekilde azaldığ (Villas-Boas ve ark., 2003; Albuquerque ve ark., 2006; Vendruscolo ve ark., 2008; Ajila ve ark., 2015; Madrera ve ark., 2017) ve hayvan besleme için biyolojik değeri olan enzim, organik asit ve antioksidan gibi bazı aktif maddelerce (Zheng ve Shetty, 2000; Joshi ve Devender, 2006; Ajila ve ark., 2011) zenginleştiği bildirilmiştir.

Altop ve ark. (2019) yürüttükleri çalışmada Aspergillus niger ile pamuk tohumu küspesi, ayçiçeği küspesi ve fındık küspesini fermente etmişler en iyi sonucu fındık küspesinde bulmuşlardır. Fermantasyon sonucunda findık küspesinin ham protein içeriğinin arttığını, yapısal karbonhidratların ise azaldığını rapor etmişlerdir. Domates posasının Pleurotus ostreatus ve Phanerochaete chrysosporium ile fermantasyonu sonucunda ham kül ve protein içeriklerinin arttığ pektin içeriklerinin önemli derecede azaldığı saptanmıştır (Yaşar ve Tosun, 2020). Kolza küspesinin Aspergillus niger ile 72 saat fermantasyonu sonucunda ham protein içeriğinin arttığı, NDF, glukozinolatlar, izotiyosiyanat ve fitik asit gibi antibesinsel faktörlerin azaldığı bildirilmiştir (Shi ve ark., 2016). Elma posasının Aspergilus'ün dört farklı suşu ile 5 günlük fermantasyonu sonucunda proteaz, pektinaz ve selülaz enzim aktivitelerinin arttığı, antibesinsel faktörlerin ise azaldığı saptanmıştır (Zhong- 
Tao ve ark., 2009). Başka bir çalışmada ise buğday kepeğinden lipaz üretimi için en ideal mikroorganizmanın Aspergillus niger olduğu tespit edilmiştir (Falony ve ark., 2006).

Bu çalışmada literatürdeki sonuçlardan hareketle modern bir biyoreaktör kullanarak Aspergillus niger mikroorganizması için en ideal $\mathrm{pH}$, karıştırma hızı ve nem içeriği ayarlanarak elma ve domates posalarını 72 saat boyunca fermantasyona uğratmak ve fermantasyon sonucunda elma ve domates posalarının besin madde içeriklerinin zenginleştirilmesi ve antibesinsel faktörlerin ise azaltılması ve sonuç olarak fonksiyonel yem elde etmek amaçlanmıştır.

\section{MATERYAL VE METOT}

Elma ve domates posaları piyasadan taze posa olarak satın alınmış ve tepsilerde $24{ }^{\circ} \mathrm{C}$ 'de hava sirkülâsyonu altında kurutulmuştur. Kurutulan posalar fermantasyon esnasında partiküller arasında uygun hava dolaşımı sağlamak için $3 \mathrm{~mm}$ elekten geçirilerek öğütülmüştür. Öğütülen posaların 120 ${ }^{\circ} C^{\prime}$ de 15 dk otoklavlanarak sterilizasyonu sağlanmıştır. DSMZ (Deutsche Sammlung von Mikroorganismen und Zellkulturen GmbH, Germany) firmasından satın alınan Aspergillus niger van Tieghem, Anamorph (ATCC® 9029TM) (A. niger) satıcı firmanın önerdiği koşullarda Malt Extract Agar'da $25{ }^{\circ} \mathrm{C}$ 'de beş gün inkübasyona bırakılarak fermantasyonda kullanılmak üzere çoğaltılarak depolanmıştır. Çalışma kapasitesi 2.5-3 litre LabforEtOH 5 (Infors Ltd., İsviçre), biyoreaktörde toplam hacim 2.5 L'yi geçmeyecek şekilde mikrobiyolojik kabin içinde katı ve sıvı ile doldurularak Tablo 1'deki koşullar altında fermente edilmiştir. Fermantasyon süresi boyunca biyoreaktör peristaltik pompaları sayesinde $\mathrm{pH}$ istenilen seviyede tutulmuştur. Fermantasyonda $\mathrm{pH}$ 'yı ideal seviyede tutmak için asit ve baz tamponu olarak sırasıyla $0.1 \mathrm{M}$ sodyum asetat $(\mathrm{pH}=1.5)$ ve $0.1 \mathrm{M}$ sodyum bikarbonat $(\mathrm{pH}=9.75)$ kullanılmıştır. Aynı koşullar altında mikroorganizma kullanılmadan da elma ve domates posaları fermente edilmiştir.

Çizelge 1. Fermantasyon koşulları ve deneme deseni

\begin{tabular}{|c|c|c|c|c|}
\hline Parametreler & Deneme 1 & Deneme 2 & Deneme 3 & Deneme 4 \\
\hline Mikroorganizma & Yok & A. niger & Yok & A. niger \\
\hline İnokulant, spor ml $\mathrm{ml}^{-1}$ & 0 & $2.1 \times 10^{6} \pm 0.03$ & 0 & $1.8 \times 10^{6} \pm 0.01$ \\
\hline Substrat & \multicolumn{2}{|c|}{ Elma posası } & \multicolumn{2}{|c|}{ Domates posas1 } \\
\hline $\mathrm{pH}$ & \multicolumn{4}{|c|}{$4.00-4.10$} \\
\hline Nem, $\%$ & \multicolumn{4}{|c|}{91} \\
\hline Sicaklık, ${ }^{\circ} \mathrm{C}$ & \multicolumn{4}{|c|}{28} \\
\hline Hava, $\mathrm{L} \mathrm{dk}^{-1}$ & \multicolumn{4}{|c|}{1.50} \\
\hline Karıştırma, rpm & \multicolumn{4}{|c|}{150} \\
\hline Örnekleme periyodu, saat & \multicolumn{4}{|c|}{24,48 ve 72} \\
\hline
\end{tabular}

Biyoreaktör sisteminden çıkan hava yine filtrelerden geçtikten sonra portatif gaz ölçüm cihazı ile $\mathrm{CO}_{2}, \mathrm{CH}_{4}$ ve $\mathrm{H}_{2} \mathrm{~S}$ gazı ölçümlerine tabi tutulmuştur. Fermantasyon süreleri sonunda steril olarak alınan yaş örneklerde mikrobiyolojik analizler TS EN ISO 21527-1/2:2008, tarafindan bildirilen koloni oluşturma birimi (kob.) metoduna göre yapılmıştır. Fermente ürünlerde organik asit (asetik, bütirik ve laktik asit) tayinleri Karabulut ve Canbolat (2005), tarafindan bildirilen titrimetrik yöntem ile yapılmıştır. Fermantasyon sonucu yaş örnekler etüvde (30-40 ${ }^{\circ} \mathrm{C}$ 'de) kurutulduktan sonra kuru madde (KM), ham kül (HK), ham protein (HP), ham selüloz (HS), ADF, NDF, ham yağ (HY) ve toplam redükte şeker (TRŞ), AOAC (1990) tarafından bildirilen ve Karabulut ve Canbolat, (2005)'de verilen metot protokollere göre tespit edilmiştir. Lignin ve metabolik enerji ise hesap yolu tespit edilmiştir. Metabolik enerji (ME) değerlerinin hesabında Janssen (1989), tarafından bildirilen formülden yararlanılmıştır.

Tanin analizleri Chemesova ve Chizhikov (2004)'a göre, pektin ise Wang ve Zhang (1999), tarafından belirtilen yönteme göre tespit edilmiştir. 
Fermentasyonun 0, 24, 48 ve 72. saatlerinde steril koşullarda bağımsız olarak 3 adet örnek alınmıştır. Örnekler kurutulduktan sonra besin madde analizleri için 3 kez tekrarlanmıştır. Böylece, her bir inkübasyonda 9 adet bağımsız ölçüm yapılmıştır. Her bir yem ve her bir maya suşu ile yapılan fermantasyon sonucu elde edilen yemlerde yürütülen analizlere ait sonuçlar general lineer model (GLM) kullanılarak varyans analizleri yapılmıştır. Analiz sonucunun önemli bulunması durumda grup ortalamaları arasındaki farklılıklar ise Duncan Çoklu Karşılaştırma Testi ile belirlenmiştir.

\section{BULGULAR VE TARTIŞMA}

Tüm fermantasyonlarda önceden belirlenen $\mathrm{pH}$ ve sıcaklık değerlerinde herhangi bir değişim olmamıştır. Fermantasyonda $\mathrm{pH}$ değerlerinde istenilen seviyesi aşması yönünde bir değişim olduğunda biyoreaktör asit/baz tampon çözeltilerden peristaltik pompaları vasıtasıyla kullanarak kısa sürede fermantasyonda $\mathrm{pH}$ 'ı istenilen seviyede tutarak başarılı bir fermantasyon olmasını sağlamıştır (Çizelge 2). Elma ve domates posasının mikroorganizma kullanılmadan yürütülen tüm fermantasyonlarında herhangi bir mikroorganizma gelişmesi, gaz çıkışı ve kuru madde (KM) oranında değişim olmamıştır.

Literatür çalışmalarında KFF'in ideal nem oranının (özellikle fungallarda) \%50-75 arası olduğu bildirilmektedir (Yarkın, 2007). Ancak bu çalışmada A. niger ile elma ve domates posasının 72 saatlik fermantasyonları \%91 gibi yüksek nem oranında gerçekleştirilmiştir. Elma ve domates posası fermantasyonlarının nem oranının yüksek olmasına karşın mikrobiyal gelişim, besin madde, antibesinsel faktörler ve organik asitler üzerine etkileri incelendiğinde $A$. niger'in yüksek nemli fermantasyonda da kullanılabileceğini göstermektedir.

Elma ve domates posasının A. niger ile 72 saatlik fermantasyonları süresi boyunca en fazla $\mathrm{CO}_{2}$ düzeyi her iki fermantasyonda da $\% 2$ olarak fermantasyonun ilk 24 . saatinde tespit edilmiştir. Fermantasyonların ilerleyen aşamasında ise azalmıştır. Elma posasının A. niger ile fermantasyonu sonucunda substratın KM oranında istatistiksel olarak bir değişim saptanmamıştır $(\mathrm{P}>0.05)$. Ancak domates posasının A. niger ile 72 saat fermantasyon sonunda KM miktarı 0. saat örneklerin KM miktarına göre \%15 oranında artmıştır $(\mathrm{P}<0.05)$. Fungal gelişim ise her iki fermantasyonda da fermantasyon süresi boyunca artmış ve bu artış istatistiksel olarak önemli $(\mathrm{P}<0.05)$ bulunmuş olup en fazla artış elma posasında fermantasyonun ilk 24 saatinde, domates posasında ise fermantasyonunda 48 saatinde meydana gelmiştir (Çizelge 2). Çalışmada analiz edilen diğer besin madde miktarları kuru madde esasına göre sunulmuştur.

Mikroorganizma kullanılmadan yürütülen fermantasyon çalışmalarında elma ve domates posasının besin madde içeriklerinde istatistiksel olarak önemli ( $\mathrm{P}>0.05)$ değişim olmamıştır (Çizelge 3). Ancak mikroorganizma kullanılarak fermantasyona tabi tutulan elma ve domates posasının besin madde kompozisyonunda önemli $(\mathrm{P}<0.05)$ değişimler tespit edilmiştir (Çizelge 3$)$.

Elma ve domates posasının A. niger ile fermantasyonu sonucunda besin madde içeriklerinde önemli $(\mathrm{P}<0.05)$ değişmeler saptanmıştır (Çizelge 4). A. niger ile elma ve domates posasının KM içeriğinde rakamsal bir değişim söz konusu ise de istatistiksel olarak bu değişim önemsizdir $(\mathrm{P}>0.05)$. Elma posasının A. niger ile fermantasyonu sonucunda ham kül (HK) içeriği önemli (P>0.05) derecede artmıştır, en fazla artış ise fermantasyonun 48. Saatinde \%98 oranında olduğu tespit edilmiştir. Diğer taraftan domates posasının HK içeriği ise fermantasyonun 24 ve 48. saatlerinde önemli $(\mathrm{P}<0.05)$ düzeyde azalırken fermantasyonun 72. saatinde başlangıç (0. saat) miktarına ile aynı düzeye kadar artmıştır. $A$. niger ile elma posasının fermantasyonunda ham protein (HP) içeriğinde istatistiksel olarak önemli bir değişim tespit edilmemiştir $(\mathrm{P}>0.05)$. Ancak domates posasının fermantasyonunda HP içeriği fermantasyonun 48 . saatinde $\% 7$ oranında artmış ancak fermantasyon sonunda 0 . saat HP içeriği ile aynı düzeye kadar düşmüştür $(\mathrm{P}<0.05)$. Her iki posanın da fungal fermantasyonu sonucunda ham yağ $(\mathrm{HY})$ 
içeriği artmıştır $(\mathrm{P}<0.05)$. Benzer şekilde elma ve domates posasının ham selüloz, ADF, NDF ve lignin içerikleri fermantasyon esnasında önemli derecede parçalanarak azaldığı tespit edilmiştir $(\mathrm{P}<0.05)$. Toplam redükte şeker (TRŞ) miktarı ise her iki fermantasyonda da önemli derecede arttığı ve en fazla artışın ise domates posasının fermantasyonunda elde edildiği saptanmıştır $(\mathrm{P}<0.05)$. TRŞ, HY ve HP içeriklerindeki artışa bağlı olarak elma ve domates posasının metabolik enerji (ME) içeriği de A. niger fermantasyonu sonucunda artmıştır.

Çizelge 2. Elma ve domates posasının A. niger ile fermantasyon süresi boyunca $\mathrm{pH}, \mathrm{CO}_{2}, \mathrm{H}_{2} \mathrm{~S}, \mathrm{CH}_{4}$, $\mathrm{KM}$ ve fungal gelişimde gözlemlenen değişiklikler

\begin{tabular}{|c|c|c|c|c|c|}
\hline \multirow{8}{*}{ 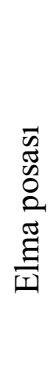 } & Parametreler & 0. saat & 24. saat & 48. saat & 72. saat \\
\hline & Sicaklık, ${ }^{\circ} \mathrm{C}$ & 28 & 28 & 28 & 28 \\
\hline & $\mathrm{pH}$ & $4.00 \pm 0.08$ & $3.96 \pm 0.06$ & $3.95 \pm 0.05$ & $3.88 \pm 0.05$ \\
\hline & $\mathrm{CO}_{2}, \%$ & 1 & 2 & 1 & 1 \\
\hline & $\mathrm{H}_{2} \mathrm{~S}, \%$ & $<\mathrm{LOD}$ & $<\mathrm{LOD}$ & $<\mathrm{LOD}$ & $<$ LOD \\
\hline & $\mathrm{CH}_{4}$ & $<\mathrm{LOD}$ & $<\mathrm{LOD}$ & $<\mathrm{LOD}$ & $<\mathrm{LOD}$ \\
\hline & $\mathrm{KM}, \%$ & $9.00 \pm 0.00$ & $9.35 \pm 0.36$ & $9.14 \pm 0.48$ & $9.46 \pm 0.31$ \\
\hline & Fungal gelişim, spor $\mathrm{g}^{-1}$ & $2.1 \times 10^{6} \pm 0.03^{\mathrm{d}}$ & $4.2 \times 10^{8} \pm 0.07^{\mathrm{c}}$ & $6.6 \times 10^{8} \pm 0.01^{\mathrm{b}}$ & $7.2 \times 10^{8} \pm 0.01^{\mathrm{a}}$ \\
\hline \multirow{7}{*}{ 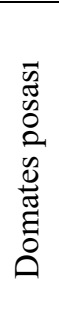 } & Sicaklık, ${ }^{\circ} \mathrm{C}$ & 28 & 28 & 28 & 28 \\
\hline & $\mathrm{pH}$ & $4.10 \pm 0.05$ & $4.12 \pm 0.01$ & $4.13 \pm 0.01$ & $4.15 \pm 0.02$ \\
\hline & $\mathrm{CO}_{2}$ & $<\mathrm{LOD}$ & 2 & $<\mathrm{LOD}$ & 1 \\
\hline & $\mathrm{H}_{2} \mathrm{~S}, \%$ & $<\mathrm{LOD}$ & $<\mathrm{LOD}$ & $<\mathrm{LOD}$ & $<\mathrm{LOD}$ \\
\hline & $\mathrm{CH}_{4}$ & $<\mathrm{LOD}$ & $<\mathrm{LOD}$ & $<\mathrm{LOD}$ & $<$ LOD \\
\hline & $\mathrm{KM}, \%$ & $9.00 \pm 0.24^{\mathrm{d}}$ & $13.32 \pm 0.03^{\mathrm{a}}$ & $12.11 \pm 0.27^{\mathrm{b}}$ & $10.33 \pm 0.19^{c}$ \\
\hline & Fungal gelişim, spor $\mathrm{g}^{-1}$ & $1.8 \times 10^{6} \pm 0.01^{\mathrm{d}}$ & $2.5 \times 10^{8} \pm 0.03^{c}$ & $1.4 \times 10^{9} \pm 0.02^{\mathrm{a}}$ & $8.9 \times 10^{8} \pm 0.01^{\mathrm{b}}$ \\
\hline
\end{tabular}

Çizelge 3. Elma ve domates posasının mikroorganizma kullanılmadan yürütülen fermantasyonda besin madde içeriklerinde meydana gelen değişim

\begin{tabular}{|c|c|c|c|c|c|}
\hline \multicolumn{2}{|r|}{ Besin Madde (KM'de) } & 0. saat & 24. saat & 48. saat & 72. saat \\
\hline \multirow{10}{*}{$\begin{array}{l}\bar{g} \\
\bar{y} \\
\vdots \\
\text { s. }\end{array}$} & $\mathrm{KM}, \%$ & $92.36 \pm 0.14$ & $92.01 \pm 0.28$ & $91.89 \pm 0.25$ & $92.01 \pm 0.20$ \\
\hline & HK, \% & $1.45 \pm 0.05$ & $1.44 \pm 0.10$ & $1.47 \pm 0.08$ & $1.51 \pm 0.10$ \\
\hline & $\mathrm{HP}, \%$ & $7.05 \pm 0.10$ & $7.08 \pm 0.32$ & $7.28 \pm 0.20$ & $7.15 \pm 0.35$ \\
\hline & HY, \% & $0.24 \pm 0.07$ & $0.22 \pm 0.05$ & $0.22 \pm 0.06$ & $0.23 \pm 0.10$ \\
\hline & $\mathrm{HS}, \%$ & $40.09 \pm 1.16$ & $40.22 \pm 1.07$ & $40.16 \pm 1.01$ & $40.04 \pm 1.25$ \\
\hline & $\mathrm{ADF}, \%$ & $56.50 \pm 0.44$ & $56.50 \pm 0.74$ & $56.41 \pm 0.55$ & $56.33 \pm 0.52$ \\
\hline & NDF, $\%$ & $66.11 \pm 1.13$ & $66.00 \pm 1.25$ & $65.58 \pm 1.05$ & $66.27 \pm 1.07$ \\
\hline & Lignin, \% & 16.41 & 16.05 & 15.58 & 16.24 \\
\hline & TRŞ & $40.10 \pm 1.75$ & $39.05 \pm 1.50$ & $39.87 \pm 1.44$ & $39.85 \pm 1.59$ \\
\hline & ME, kkal kg-1 & 1648.59 & 1645.04 & 1651.26 & 1647.28 \\
\hline \multirow{10}{*}{ 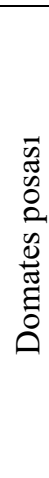 } & $\mathrm{KM}, \%$ & $93.06 \pm 0.03$ & $94.01 \pm 0.03$ & $93.72 \pm 0.05$ & $93.27 \pm 0.05$ \\
\hline & HK, \% & $4.34 \pm 0.10$ & $4.30 \pm 0.07$ & $4.31 \pm 0.05$ & $4.27 \pm 0.10$ \\
\hline & $\mathrm{HP}, \%$ & $21.22 \pm 0.10$ & $21.00 \pm 0.08$ & $21.10 \pm 0.12$ & $21.14 \pm 0.06$ \\
\hline & HY, \% & $11.79 \pm 0.03$ & $11.74 \pm 0.05$ & $11.71 \pm 0.06$ & $11.77 \pm 0.05$ \\
\hline & $\mathrm{HS}, \%$ & $37.20 \pm 0.05$ & $37.12 \pm 0.10$ & $37.14 \pm 0.08$ & $37.21 \pm 0.13$ \\
\hline & $\mathrm{ADF}, \%$ & $56.41 \pm 0.06$ & $56.41 \pm 0.25$ & $56.51 \pm 0.18$ & $56.43 \pm 0.20$ \\
\hline & NDF, $\%$ & $62.34 \pm 0.70$ & $62.25 \pm 0.68$ & $62.14 \pm 0.52$ & $61.85 \pm 0.67$ \\
\hline & Lignin, $\%$ & 19.21 & 19.08 & 19.20 & 18.55 \\
\hline & TRŞ & $24.77 \pm 1.35$ & $23.81 \pm 1.22$ & $24.07 \pm 0.95$ & $24.14 \pm 1.01$ \\
\hline & ME, kkal kg-1 & 2523.75 & 2525 & 2541.05 & 2521.15 \\
\hline
\end{tabular}


Çizelge 4. Elma ve domates posasının A. niger ile fermantasyonunda besin madde içeriklerinde meydana gelen değişim

\begin{tabular}{|c|c|c|c|c|c|}
\hline \multirow{11}{*}{ 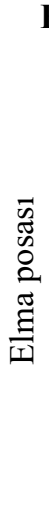 } & esin Madde (KM'de) & 0. saat & 24. saat & 48. saat & 72. saat \\
\hline & $\mathrm{KM}, \%$ & $92.36 \pm 0.14$ & $94.45 \pm 0.15$ & $94.65 \pm 0.06$ & $93.74 \pm 0.09$ \\
\hline & $\mathrm{HK}, \%$ & $1.45 \pm 0.05^{\mathrm{b}}$ & $2.49 \pm 0.09^{\mathrm{a}}$ & $2.87 \pm 0.47^{\mathrm{a}}$ & $2.27 \pm 0.43^{\mathrm{a}}$ \\
\hline & $\mathrm{HP}, \%$ & $7.05 \pm 0.10$ & $6.44 \pm 0.05$ & $7.30 \pm 0.05$ & $6.51 \pm 0.66$ \\
\hline & $\mathrm{HY}, \%$ & $0.24 \pm 0.07^{c}$ & $1.54 \pm 0.02^{\mathrm{a}}$ & $1.59 \pm 0.03^{\mathrm{a}}$ & $0.81 \pm 0.03^{b}$ \\
\hline & $\mathrm{HS}, \%$ & $40.09 \pm 1.16^{\mathrm{a}}$ & $30.53 \pm 0.07^{\mathrm{b}}$ & $28.12 \pm 0.43^{\mathrm{c}}$ & $26.90 \pm 0.68^{\mathrm{d}}$ \\
\hline & $\mathrm{ADF}, \%$ & $56.50 \pm 0.44^{\mathrm{a}}$ & $41.52 \pm 0.02^{\mathrm{b}}$ & $38.44 \pm 0.40^{\mathrm{c}}$ & $39.65 \pm 0.18^{c}$ \\
\hline & NDF, $\%$ & $66.11 \pm 1.13^{\mathrm{a}}$ & $52.51 \pm 0.08^{\mathrm{b}}$ & $48.67 \pm 0.07^{\mathrm{c}}$ & $47.72 \pm 0.21^{\mathrm{c}}$ \\
\hline & Lignin, $\%$ & 16.41 & 10.99 & 10.32 & 12.75 \\
\hline & TRŞ & $40.10 \pm 1.75^{\mathrm{b}}$ & $41.06 \pm 0.06^{\mathrm{b}}$ & $46.72 \pm 0.69^{\mathrm{a}}$ & $45.77 \pm 0.65^{\mathrm{a}}$ \\
\hline & ME, kkal kg-1 & 1648.59 & 1995.966 & 2257.44 & 2124.41 \\
\hline \multirow{10}{*}{ 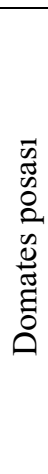 } & KM, \% & $93.06 \pm 0.03$ & $95.26 \pm 0.02$ & $95.64 \pm 0.01$ & $95.67 \pm 0.05$ \\
\hline & HK, \% & $4.34 \pm 0.10^{\mathrm{a}}$ & $3.17 \pm 0.12^{b}$ & $3.13 \pm 0.20^{\mathrm{b}}$ & $4.55 \pm 0.22^{\mathrm{a}}$ \\
\hline & $\mathrm{HP}, \%$ & $21.22 \pm 0.10^{\mathrm{b}}$ & $21.59 \pm 0.38^{b}$ & $22.79 \pm 0.36^{\mathrm{a}}$ & $21.20 \pm 0.06^{\mathrm{b}}$ \\
\hline & $\mathrm{HY}, \%$ & $11.79 \pm 0.03^{b}$ & $12.47 \pm 0.03^{\mathrm{a}}$ & $12.47 \pm 0.02^{\mathrm{a}}$ & $12.28 \pm 0.17^{\mathrm{a}}$ \\
\hline & $\mathrm{HS}, \%$ & $37.20 \pm 0.05^{\mathrm{a}}$ & $27.14 \pm 0.30^{\mathrm{b}}$ & $25.03 \pm 0.09^{\mathrm{b}}$ & $24.58 \pm 3.75^{b}$ \\
\hline & ADF, $\%$ & $56.41 \pm 0.06^{\mathrm{a}}$ & $43.73 \pm 0.50^{\mathrm{b}}$ & $41.85 \pm 0.02^{\mathrm{c}}$ & $43.93 \pm 0.03^{b}$ \\
\hline & $\mathrm{NDF}, \%$ & $62.34 \pm 0.70^{\mathrm{a}}$ & $60.32 \pm 0.20^{\mathrm{b}}$ & $58.14 \pm 0.63^{\mathrm{c}}$ & $59.71 \pm 0.13^{\mathrm{c}}$ \\
\hline & Lignin, $\%$ & 19.21 & 16.59 & 16.82 & 19.35 \\
\hline & TRŞ & $24.77 \pm 1.35^{\mathrm{d}}$ & $29.19 \pm 0.35^{\mathrm{c}}$ & $31.68 \pm 1.75^{\mathrm{b}}$ & $35.73 \pm 0.01^{\mathrm{a}}$ \\
\hline & ME, kkal kg-1 & 2523.75 & 2730.70 & 2854.9 & 2903.9 \\
\hline
\end{tabular}

a,b,c,d: Faklı harfler ile gösterilen ortalamalar arasında önemli $(\mathrm{P}<0.05)$ farklar vardır.

Domates posasının HK içeriği fermantasyon sonucunda değişmezken, elma posasının HK içeriği fermantasyonla birlikte önemli derecede artmıştır. Elma posasının HK içeriğindeki artış literatürdeki sonuçlarla büyük uyum içerisindedir (Assi ve King 2008; Lateef ve ark., 2008; Díaz-Godínez, 2012; Ajila ve ark., 2015; Madrera ve ark., 2017; Yaşar ve Tosun, 2019). Altop ve ark. (2018) fermantasyon esnasında mikroorganizmalar fitaz enzimi salgıladıklarını bunun neticesinde kompleks formdaki fosforların parçalanarak fermente son ürünün HK içeriklerinin artmasına neden olduğunu belirtmişlerdir. KFF ile fermantasyonda kullanılan substratların HP içeriklerinde önemli derecede artış elde edildiğine dair literatürde sonuçlar mevcuttur (Aggelopoulos ve ark. 2014; Kutshik ve ark., 2016; Al-Farsi ve ark., 2019; Bölükbaşı Aktaş ve ark., 2019). Ancak, bu çalışmadaki HP sonuçları literatürdeki sonuçlarla benzerlik göstermemiştir. Bu çalışmada elma posasının HP içeriği fermantasyon sonucunda istatistiksel olarak önemli bir değişim tespit edilmemiştir. Domates posasının fermantasyonunda ise 48 saatinde $\% 7$ oranında bir artış gözlemlense de fermantasyon sonucunda bu artış kaybolmuştur. Villas-Boas ve ark. (2003) fermantasyonda $\left(\mathrm{NH}_{4}\right)_{2} \mathrm{SO}_{4}$ gibi nitrojen kaynaklarının ilave edilmesi substratın HP içeriklerinin önemli derecede artırdığını belirtmiştir. Bu çalışmada substrata katkı maddesi olarak herhangi bir nitrojen kaynağı ilave edilmemiştir. HP açısından benzerlik göstermemesinin nedeni fermantasyona nitrojen kaynağının ilave edilmemesi nedeniyle mikroorganizmaların nitrojen kaynağı olarak HP'yi parçaladıkları düşüncesi ağır basmaktadır. Bu çalışmada her iki posasında HY içeriklerinde artış olmuştur. En fazla HY içeriğindeki artış ise elma posasının 48. saatinde \%563 oranında olmuştur. KFF ile substratların HY içeriğinin değişimde çelişkili sonuçlar vardır. Bazı çalışmalarda arttığına (Joshi ve Devender, 2006; You-Ling ve ark., 2013; Madrera ve ark., 2017; Altop ve ark., 2018) ve bazılarında azaldığına (Lateef ve ark., 2008; Agbo ve Prah, 2014; Jannathulla ve ark., 2018; Bölükbaşı Aktaş ve ark., 2019) dair birçok çalışma mevcuttur. Bhargav ve ark. (2008) fungal mikroorganizmalarla sıvı ve katı faz fermantasyonda fungal mikroorganizmaların fitik asit gibi antibesinsel faktörleri parçalayarak çoklu doymamış yağ asitlerine dönüştürdüklerini belirtmiştir. Bu çalışmada HY içeriği artarken tanin 
içeriğinin önemli derecede azalmıştır. Bu çalışmada da A. niger'in tanini parçalayarak çoklu doymamış yağ asitlerine dönüştürdügü düşünülmektedir. A. niger ile her iki posasının da yapısal karbonhidratları (HS, ADF, NDF ve lignin) önemli derecede azalmıştır. KFF ile yapısal karbonhidratların azaldığına dair birçok çalışma mevcut olup bu çalışmadaki sonuçlar literatürdeki sonuçlarla paralellik göstermektedir (Lateef ve ark., 2008; Altop ve ark., 2018). Krishna (2005) ve Aderemi ve Nworgu, (2007) mikrobiyal fermantasyonda mikroorganizmaların karbon kaynağı olarak yapısal karbonhidratları kullanmak için selülaz gibi enzim salgıladıklarını ve bunun sonucunda HS, ADF, NDF ve lignin azaldığını belirtmişlerdir. Bu çalışmada da A. niger'in karbon kaynağı olarak yapısal karbonhidratları kullandığı bunun neticesinde de HS, ADF, NDF ve lignin azaldığını düşünülmektedir. Genellikle mikrobiyal fermantasyonda mikroorganizmaların karbon kaynağı olarak ilk suda çözünebilir karbonhidratları daha sonra kompleks karbonhidratları tükettiklerine dair literatürde sonuçlar mevcuttur (Xie ve ark. 2016; Kutshik ve ark., 2016; Altop ve ark., 2019). Ancak bu çalışmada A. niger ile fermente edilen her iki posanın da TRŞ içeriğinin arttığı saptanmıştır. Bu çalışmada elde edilen sonuçlar literatürle uyum göstermemektedir.

Çizelge 5'de görüleceği üzere mikroorganizma kullanılmadan yürütülen elma ve domates posasının fermantasyon çalışmasında asetik asit (AA), bütirik asit (BA), laktik asit (LA) ve toplam organik asit (TOA) içeriklerinde istatistiksel olarak önemli bir değişim saptanmamıştır $(\mathrm{P}>0.05)$. Ancak A. niger ile yürütülen fermantasyonda organik asit içeriklerinin önemli derecede değiştiği tespit edilmiştir $(\mathrm{P}<0.05)$ (Çizelge 6).

Çizelge 5. Elma ve domates posasının mikroorganizma kullanılmadan yürütülen fermantasyonunda organik asit içeriklerinde meydana gelen değişim

\begin{tabular}{lccccc}
\hline Substrat & Organik Asit & 0. saat & 24. saat & 48. saat & 72. saat \\
\hline Elma posas1 & AA, \% & $0.15 \pm 0.01$ & $0.12 \pm 0.05$ & $0.12 \pm 0.05$ & $0.10 \pm 0.05$ \\
& BA, \% & $0.05 \pm 0.02$ & $0.05 \pm 0.02$ & $0.05 \pm 0.02$ & $0.05 \pm 0.02$ \\
& LA, \% & $2.05 \pm 0.11$ & $2.11 \pm 0.10$ & $2.10 \pm 0.14$ & $2.07 \pm 0.10$ \\
& TOA, \% & $2.25 \pm 0.14$ & $2.28 \pm 0.10$ & $2.27 \pm 0.12$ & $2.22 \pm 0.09$ \\
\hline Domates posas1 & AA, \% & $0.41 \pm 0.05$ & $0.38 \pm 0.10$ & $0.32 \pm 0.08$ & $0.40 \pm 0.10$ \\
& BA, \% & $0.00 \pm 0.00$ & $0.00 \pm 0.00$ & $0.00 \pm 0.00$ & $0.00 \pm 0.00$ \\
& LA, \% & $1.12 \pm 0.03$ & $1.14 \pm 0.11$ & $1.25 \pm 0.10$ & $1.20 \pm 0.14$ \\
& TOA, \% & $1.53 \pm 0.02$ & $1.52 \pm 0.05$ & $1.57 \pm 0.04$ & $1.60 \pm 0.09$ \\
\hline
\end{tabular}

a,b,c,d: Faklı harfler ile gösterilen ortalamalar arasında önemli $(\mathrm{P}<0.05)$ farklar vardır

Elma posasının fungal ile fermantasyonu sonucunda AA ve BA içeriğini rakamsal olarak etkilese de istatistiksel olarak önemsiz bulunmuştur $(\mathrm{P}>0.05)$. Benzer şekilde fermantasyon domates posasının $\mathrm{BA}$ içeriğini de etkilememiştir $(\mathrm{P}>0.05)$. Diğer taraftan domates posasının fermantasyon sonunda AA içeriği \%19 oranında azalmıştır $(\mathrm{P}<0.05)$. Her iki posanın da fermantasyon sonunda LA içeriklerinin fermantasyon ile birlikte \% 195-500 oranları arasında arttığ tespit edilmiştir $(\mathrm{P}<0.05)$. LA içeriğine bağlı olarak posaların TOA içerikleri de önemli düzeyde artmıştır $(\mathrm{P}<0.05)$.

A. niger her iki posanında AA ve BA içeriklerini çok fazla etkilemezken LA içeriği ve buna bağlı olarak da TOA içeriği önemli düzeyde artmıştır. KFF ile organik asit üretilebileceğine dair araştırmalar mevcuttur (Raimbault, 1998; Singhaniaa ve ark., 2009; Afşin, 2010; Kurt ve Büyükalaca, 2010; Özşölen 2010; Ravichandran ve Vimala, 2012; Yaşar ve Tosun, 2019). Bu çalışmadaki LA ve TOA içeriğindeki artış literatürdeki sonuçlarla benzerlik göstermektedir.

Elma ve domates posasının mikroorganizma kullanılmadan yürütülen 72 saatlik fermantasyonu sonucunda tanin ve pektin içeriklerinde rakamsal bir değişim olsa da istatistiksel olarak bu değişim 
önemsiz ( $\mathrm{P}>0.05$ ) bulunmuştur (Çizelge 6). Diğer taraftan domates ve elma posasının A. niger ile yürütülen fermantasyonlarda, tanin ve pektin içeriklerinin önemli $(\mathrm{P}<0.05)$ şekilde değiştiği gözlenmiştir (Çizelge 7).

Çizelge 6. Elma ve domates posasının A. niger ile yürütülen fermantasyonunda organik asit içeriklerinde meydana gelen değişim

\begin{tabular}{cccccc}
\hline Substrat & Organik Asit & 0. saat & 24. saat & 48. saat & 72. saat \\
\hline Elma posas1 & AA, \% & $0.15 \pm 0.01$ & $0.24 \pm 0.10$ & $0.24 \pm 0.10$ & $0.24 \pm 0.10$ \\
& BA, \% & $0.05 \pm 0.02$ & $0.01 \pm 0.03$ & $0.01 \pm 0.03$ & $0.01 \pm 0.03$ \\
& LA, \% & $2.05 \pm 0.11^{\mathrm{d}}$ & $5.55 \pm 0.21^{\mathrm{c}}$ & $7.70 \pm 0.21^{\mathrm{a}}$ & $6.01 \pm 0.05^{\mathrm{b}}$ \\
& TOA, \% & $2.25 \pm 0.14^{\mathrm{d}}$ & $5.80 \pm 0.14^{\mathrm{c}}$ & $7.95 \pm 0.14^{\mathrm{a}}$ & $6.26 \pm 0.02^{\mathrm{b}}$ \\
\hline Domates posas1 & AA, \% & $0.41 \pm 0.05^{\mathrm{a}}$ & $0.49 \pm 0.10^{\mathrm{a}}$ & $0.31 \pm 0.96^{\mathrm{ab}}$ & $0.33 \pm 0.02^{\mathrm{b}}$ \\
& BA, \% & $0.0 \pm 0.00$ & $0.0 \pm 0.00$ & $0.0 \pm 0.00$ & $0.0 \pm 0.00$ \\
& LA, \% & $1.12 \pm 0.03^{\mathrm{b}}$ & $6.69 \pm 0.36^{\mathrm{a}}$ & $7.19 \pm 0.61^{\mathrm{a}}$ & $6.58 \pm 0.30^{\mathrm{a}}$ \\
& TOA, \% & $1.53 \pm 0.02^{\mathrm{c}}$ & $6.54 \pm 0.29^{\mathrm{b}}$ & $7.50 \pm 0.33^{\mathrm{a}}$ & $6.91 \pm 0.27^{\mathrm{ab}}$
\end{tabular}

a,b,c,d: Faklı harfler ile gösterilen ortalamalar arasında önemli $(\mathrm{P}<0.05)$ farklar vardır

Çizelge 6. Elma ve domates posasının mikroorganizma kullanılmadan yürütülen fermantasyonunda tanin ve pektin içeriklerindeki değişim

\begin{tabular}{lccc}
\hline Antibesinsel Faktörler & & Tanin, $\%$ & Pektin, \% \\
\hline Elma posas1 & 0. saat & $18.64 \pm 0.13$ & $6.15 \pm 0.07$ \\
& 24. saat & $18.57 \pm 0.03$ & $6.05 \pm 0.85$ \\
& 48. saat & $18.60 \pm 0.05$ & $6.14 \pm 0.48$ \\
& 72. saat & $18.60 \pm 0.06$ & $6.27 \pm 0.75$ \\
\hline Domates posas1 & 0. saat & $13.17 \pm 0.84$ & $6.36 \pm 0.32$ \\
& 24. saat & $13.00 \pm 0.05$ & $6.15 \pm 0.10$ \\
& 48. saat & $13.14 \pm 0.05$ & $6.15 \pm 0.05$ \\
& 72. saat & $13.20 \pm 0.10$ & $6.27 \pm 0.15$ \\
\hline
\end{tabular}

a,b,c,d: Faklı harfler ile gösterilen ortalamalar arasında önemli $(\mathrm{P}<0.05)$ farklar vardır

A. niger ile elma ve domates posasının tanin içerikleri fermantasyon süresince azalmış ve fermantasyon sonunda elma posasında $\% 89$, domates posasında ise $\% 81$ oranında önemli bir azalma tespit edilmiştir $(\mathrm{P}<0.05)$. Diğer taraftan fermantasyon sonunda elma posasının pektin içeriği \%103 oranında artarken domates posasının pektin içeriği \%30 oranında azalmıştır $(\mathrm{P}<0.05)$.

Çizelge 7. Elma ve domates posasının A. niger ile yürütülen fermantasyonunda tanin ve pektin içeriklerindeki

\begin{tabular}{lccc}
\hline Antibesinsel Faktörler & Tanin, $\%$ & Pektin, \% \\
\hline Elma posas1 & 0. saat & $18.64 \pm 0.13^{\mathrm{a}}$ & $6.15 \pm 0.07^{\mathrm{c}}$ \\
& 24. saat & $2.27 \pm 0.01^{\mathrm{b}}$ & $16.74 \pm 0.95^{\mathrm{a}}$ \\
& 48. saat & $2.15 \pm 0.001^{\mathrm{b}}$ & $12.50 \pm 1.08^{\mathrm{b}}$ \\
& 72. saat & $2.14 \pm 0.003^{\mathrm{b}}$ & $12.50 \pm 1.08^{\mathrm{b}}$ \\
\hline Domates posas1 & 0. saat & $13.17 \pm 0.84^{\mathrm{a}}$ & $6.36 \pm 0.32^{\mathrm{a}}$ \\
& 24. saat & $1.83 \pm 0.03^{\mathrm{d}}$ & $3.45 \pm 0.16^{\mathrm{c}}$ \\
48. saat & $1.99 \pm 0.01^{\mathrm{c}}$ & $4.50 \pm 0.10^{\mathrm{b}}$ \\
\hline
\end{tabular}

a,b,c,d: Faklı harfler ile gösterilen ortalamalar arasında önemli $(\mathrm{P}<0.05)$ farklar vardır

A. niger ile yürütülen fermantasyon sonunda her iki posanın da tanin içeriği azalmıştır. Bu çalışmadaki sonuçların literatürdeki sonuçlar ile büyük benzerlik göstermektedir. Mikrobiyal fermantasyonda mikroorganizmaların tannaz enzimi salgıladığı ve bunun sonucunda tanin içeriğinin 
gallik asit, kateşin, glukoz ve gallikateşin gibi daha küçük moleküllere parçalandığını saptanmıştır (Rodriguez ve ark., 2008; Nazarni ve ark., 2016; Shanga ve ark., 2019; Yaşar ve Tosun, 2020). Bu çalışmada da A. niger'in tanini daha küçük moleküllere parçaladığı bunun sonucunda da her iki fermantasyonda da tanin içeriğinin azaldığı düşünülmekte, ancak enzim analizi yapılmadığı için bu nedenden dolayı mı yoksa başka bir nedenden dolayı mı azaldığı tam anlaşılamamıştır. Elma posasının fungal fermantasyonu sonucunda pektin içeriğinin artarken domates posasının pektin içeriği önemli düzeyde azalmıştır. Literatürdeki sonuçlara bakıldığında farklı mikroorganizmalarla yürütülen fermantasyon çalışmalarında pektin içeriklerinde benzer sonuçların olmadığı bazı çalışmalarda azalırken (Villas-Boas ve ark., 2003; Ruiz-Aguilar ve ark., 2004; Zhong-Tao ve ark., 2009; Yaşar ve Tosun, 2020) bazılarında arttığ (Altop ve ark., 2018; Tosun ve Yaşar, 2020) tespit edilmiştir.

\section{SONUÇ}

Elma ve domates posalarının A. niger ile fermantasyonu sonucunda yapısal karbonhidratların ve bazı antibesinsel faktörlerin azalması ve laktik asit içeriğinin önemli derecede artması elde edilen fermente son ürünün hayvan beslemede özellikle de kanatlıların beslenmesinde organik asitlerce zengin katkı maddesi olarak kullanılma olanağı artmıştır, ancak elde edilen bu sonuçların hayvan denemesi ile de desteklenmesine ihtiyaç olduğu sonucuna varılmıştır.

\section{TEŞEKKÜR}

Bu araştırma TÜBİTAK VHAG 1001 tarafından desteklenmiştir (Proje No:124O629). Finansal desteklerinden dolayı teşekkür ederiz.

\section{KAYNAKLAR}

Abdollahzadeh F, Pirmohammadi R, Fatehi F, Bernousi I, 2010. Effect of feeding ensiled mixed tomato and apple pomace on performance of holstein dairy cows. Slovak Journal of Animal Science, 43(1): 31-35.

AboSiada OA, Negm MS, Basiouny ME, Fouad MA, Elagroudy S, 2017. Nutrient enrichment of agro-1ndustrial waste using solid state fermentation. Microbiology Research Journal International, 22(1): 1-11.

Aderemi F, Nworgu F, 2007. Nutritional status of cassava peels and root sieviate biodegraded with Aspergillus niger. American-Eurasian Journal of Agriculture And Environment Science, 2: 308-311.

Afşin M, 2010. Katı Faz Fermantasyon (Solıd State Fermentatıon; SSF) Yöntemiyle Bacillus Licheniformis ATCC 14580'den Proteaz Üretimi, Dicle Üniversitesi Fen Bilimleri Enstitüsü, Yüksek Lisans Tezi (Basılmış).

Agbo NW, Prah CD, 2014. Evaluation of fermentation period on the proximate composition and tannin concentration of sheanut (Vitellaria paradoxa) meal. Journal of Microbiology and Biotechnology Research, 4(1): 21-27.

Aggelopoulos T, Katsieris K, Bekatorou A, Pandey A, Banat IM, Koutinas AA, 2014. Solid state fermentation of food waste mixtures for single cell protein, aroma volatiles and fat production. Food Chemistry, 145(4): 710-716.

Ajila CM, Brar SK, Verma M, Tyagi RD, Valéro JR, 2011. Solid-state fermentation of apple pomace using Phanerocheate chrysosporium - Liberation and extraction of phenolic antioxidants. Food Chemistry, 126: 1071-1080.

Ajila CM, Sarma SJ, Brar SK, Godbout S, Cote M, Guay F, Verma M, Valero JR, 2015. Fermented apple pomace as a feed additive to enhance growth performance of growing pigs and its effects on emissions. Agriculture, 5(2): 313-329.

Al-Betawi NA, 2005. Preliminary study on tomato pomace as unusual feedstuffin broiler diets. Pakistan Journal of Nutrition, 4(1): 57-63.

Albuquerque P, Koch M, Trossini F, Esposito TGE, Ninow JL, 2006. Production of Rhizopus oligosporus protein by solid state fermentation of apple pomace. Brazilian Archives of Biology and Technology, 49: 91-100. 
Al-Farsi M, Bakir AA, Marzouqi HA, Thomas R, 2019. Production of single cell protein from date waste. Materials Research Proceedings, 11: 302-312.

Altop A, Coskun I, Filik G, Kucukgul A, Bekiroglu YG, Cayan H, Gungor E, Sahin A, Erener G, 2018. Amino acid, mineral, condensed tannin, and other chemical contents of olive leaves (Olea europaea L.) processed via solid-state fermentation using selected Aspergillus niger strains. Ciencia a Investigacion Agraria, 45(2): 220-230.

Altop A, Güngör E, Erener G, 2019. Improvement of nutritional quality of some oilseed meals through solid state fermentation using Aspergillus niger. Turkish Journal of Agriculture - Food Science and Technology, 7(9): 1411-1414.

AOAC 1990. Official method of analysis. 15th ed., pp.66-88. Association of official analytical chemists, Washington, DC, USA.

Assi JA, King AJ, 2008. Manganese amendment and pleurotus ostreatus treatment to convert tomato pomace for inclusion in poultry feed. Poultry Science, 87: 1889-1896.

Bhargav S, Panda BP, Ali M, Javed S, 2008. Solid-state fermentation: An overview. Chemical and Biochemical Engineering Quarterly, 22(1): 49-70.

Bölükbaşı Aktaş ŞC, Dumlu B, Ahmadova R, 2019. Katıfaz fermentasyonu ile arpanın besin değerinin iyileştirilmesi. Atatürk Üniversitesi Veteriner Bilimleri Dergisi, 14(3): 315-323.

Chemesova II, Chizhikov DV, 2004.Determination of tannin content in rhizomes of Comarum palustre L. and its tincture by spectrophotometric method. Rastitel'nye Resursy, 40(3): 122-130.

Díaz-Godínez G, 2012. Production of laccases by Pleurotus ostreatus in solid-state and submerged fermentation. Biotechnology of Microbial Enzymes, A: 99-121.

Duru AA, Kaya Ş, 2015. Zeytin posası silajının hayvan beslemede kullanım olanakları. Mustafa Kemal Üniversitesi Ziraat Fakültesi Dergisi, 20(1): 64-71.

Falony G, Armas JC, Mendoza JCD, Hernández JLM, 2006. Production of extracellular lipase from Aspergillus niger by solid-state fermentation. Food Technology and Biotechnology, 44 (2): 235-240.

Jannathulla R, Dayal JS, Ambasankar K, Muralidhar M, 2018. Effect of Aspergillus niger fermented soybean meal and sunflower oil cake on growth, carcass composition and haemolymph indices in Penaeus vannamei Boone, 1931. Aquaculture, 486(3): 1-8.

Janssen WMMA, 1989. European Table of Energy Values for Poultry Feedstuffs. Spelderholt Institute for Poultry Research and Information Services, ISBN 9071463273, 9789071463273, S: 104.

Joshi VK, Devender A, 2006. Solid state fermentation of apple pomace for the production of value added products. Natural Product Radiance, 5(4): 289- 296.

Karabulut, A., Canbolat, Ö., 2005. Yem Değerlendirme ve Analiz Yöntemleri. Uludağ Üniversitesi Yayınlar1 No:2.05.048.0424, s.63-132 ve 356-360 Bursa-Türkiye.

King AJ, Zeidler G, 2004. Tomato pomace may be a good source of vitamin E in broiler diets. California Agriculture, 58(1): 59-62.

Krishna CH, 2005. Solid-state fermentation systems- an overview. Critical Reviews in Biotechnology, 25: 1-30.

Kurt S, Buyukalaca S, 2010. Yield performances and changes in enzyme activities of Pleurotus spp. (P. ostreatus and $P$. sajor-caju) cultivated on different agricultural wastes. Bioresource Technology, 101: 3164-3169.

Kutshik JR, Usman AM, Ali-Dunkrah U, 2016. Comparative study of protein enrichment of lignocellulose wastes using baker's yeast (Saccharomyces cerevisiae) for Animal Feeds. Journal of Biotechnology and Biochemistry, 2(7): 73-77.

Lateef A, Oloke JK, Kana EBG, Oyeniyi SO, Onifade OR, Oyeleye AO, Oladosu OC, Oyelami AO, 2008. Improving the quality of agro-wastes by solid-state fermentation: enhanced antioxidant activities and nutritional qualities. World Journal of Microbiology and Biotechnology, 24(10): 2369-2374.

Madrera RR, Bedrinana RP, Valles BS, 2017. Enhancement of the nutritional properties of apple pomace by fermentation with autochthonous yeasts. Food Science and Technology, 79(6):27-33.

Mukherjee R, Chakraborty R, Dutta A, 2016. Role of fermentation in improving nutritional quality of soybean meal a review. Asian-Australasian Journal of Animal Sciences, 29: 1523-1529. 
Nazarni R, Purnama D, Umar S, Eni H, 2016. The effect of fermentation on total phenolic, flavonoid and tannin content and its relation to antibacterial activity in jaruk tigarun (Crataeva nurvala, Buch HAM). International Food Research Journal, 23(1): 309-315.

Özşölen F, 2010. Production of ligninolytic enzymes with solid state fermentation, Eskişehir Osmangazi Üniversitesi Fen Bilimleri Enstitüsü, Yüksek Lisans Tezi (Basılmış).

Pandey A, 2003. Solid-state fermentation. Biochemical Engineering Journal, 13: 81-84.

Raimbault M,1998. General and microbiological aspects of solid substrate fermentation. Electronic Journal of Biotecnology, 1(3): 1-15.

Ravichandran S, Vimala R, 2012. Solid state and submerged fermentation for the production of bioactive substances: a comparative study. International Journal of Science and Nature, 3(3): 480-486.

Rodríguez H, Rivas B, Cordovés CG, Muñoz R, 2008. Degradation of tannic acid by cell-free extracts of Lactobacillus plantarum. Food Chemistry, 107(2): 664-670.

Ruiz-Aguilar GM, Rios-Leal E, Tomasini-Campocosio A, Veloz-Rodriguez R, Barajas-Aceves M, RodriguezVazquez R, 2004. Effect of culture parameters on the degradation of hydrolyzable tannin extracted from cascalote by Aspergillus niger. Bulletin of Environmental Contamination and Toxicology, 73(1): 45-52.

Shanga YF, Cao H, Ma YL, Zhang C, Ma F, Wang CX, Ni XL, Lee WJ, Wei ZJ, 2019. Effect of lactic acid bacteria fermentation on tannins removal in Xuan Mugua fruits. Food Chemistry, 274(5): 118-122.

Shi C, He J, Yu J, Yu B, Mao X, Zheng P, Huang Z, Chen D, 2016. Physicochemical properties analysis and secretome of Aspergillus niger in fermented rapeseed meal. PLoS ONE 11(4): 1-8.

Singhaniaa RR, Patel AK, Soccol CR, Pandey A, 2009. Recent advances in solidstate fermentation. Journal Biochemical Engineering, 44: 13-18.

Tosun R, Yaşar S, 2020. Nutritional enrichment of apple pomace by fungal fermentations. Kahramanmaraş Sütçü İmam Üniversitesi Tarım ve Doğa Dergisi, 23(3): 754-761.

TS EN ISO 21527-1/2, 2008. Erişim Tarihi:25.04.2017. intweb.tse.org.tr

Vasta V, Nudda A, Cannas A, Lanza M, Priolo A. 2008. Alternative feed resources and their effects on the quality of meat and milk from small ruminants. Animal Feed Science and Technology, 147: 223-246.

Vendruscolo F, Albuquerque PM, Streit F, Esposito E, Ninow JL, 2008. Apple pomace: A versatile substrate for biotechnological applications. Critical Reviwers in Biotechnology, 28(1): 1-12.

Villas-Boas SG, Esposito E, De Mendonca MM, 2003. Bioconversion of apple pomace into a nutritionally enriched substrate by Candida utilis and Pleurotus ostreatus. World Journal of Microbiology and Biotechnology, 19(5):461-467.

Wadhwa M, Bakshi MPS, 2016. Application of wastederived proteins in the animal feed industry. Oxford: Academic Press, s.161-192. Oxford-England.

Wang XP, Zhang WY, 1999. Study on the determination and utilization of the pectin in haw. Quarterly of Forest By-Product and Speciality in China, 9(1): 13-14.

Weiss, WP, Frobose DL, Koch ME, 1997. Wet tomato pomace ensiled with corn plants for dairy cows. Journal of Dairy Science, 80: 2896-2900.

Xie PJ, Huang LX, Zhang CH, Zhang YL, 2016. Nutrient assessment of olive leaf residues processed by solidstate fermentation as an innovative feedstuff additive. Journal of Applied Microbiology, 121(1): 28-40.

Yannakopoulos AL, Tserveni-Gousi AS, Cristaki EV, 1992. Effect of locally produced tomato meal on the performance and the egg quality of laying hens. Animal Feed Science and Technology, 36(1-2): 53-57.

Yarkın Z, 2007. İki farklı fermantasyon tekniği ile Aspergillus sclerotiorum'dan Amilaz üretimi ve nişasta hidrolizinde kullanılması, Trakya Üniversitesi Fen Bilimler Enstitüsü, Yüksek Lisans Tezi (Basılmış).

Yaşar S, Tosun R, 2019. Increased organic acid production and decreased phytate phosphorus by high level of water content of Bacillus subtilis ATCC PTA-6737 fermentation of soybean meal. Bulletin UASVM Animal Science and Biotechnologies, 76(1): 1-8.

Yaşar S, Tosun R, 2020. Improving nutritional qualities of tomato pomace by Pleurotus ostreatus and Phanerochaete chrysosporium fermentation. Kahramanmaraş Sütçü İmam Üniversitesi Tarım ve Doğa Dergisi, 23(2): 528-536. 
Yıldız G, Dikicioğlu T, Saçaklı P, 1998. Yumurta tavuğu rasyonlarında kurutulmuş elma posası ve enzim kullanılması. Türk Veteriner Hekimliği Dergisi, 10(3): 34-39.

You-Ling G, Cai-Sheng W, Qiu-Hua Z, Guo-Ying Q, 2013. Optimization of solidstate fermentation with Lactobacillus brevis and Aspergillus oryzae for trypsin nnhibitor degradation in soybean meal. Journal of Integrative Agriculture, 12(5): 869-876.

Zheng ZX, Shetty K, 2000. Solid state production of polygalacturonase by Lentinusedodes using fruit processing wastes. Process Biochemistry, 35(8): 825-830.

Zhong-Tao S, Lin-Mao T, Cheng L, Jin-Hua D, 2009. Bioconversion of apple pomace into a multienzyme biofeed by two mixed strains of Aspergillus niger in solid state fermentation. Electronic Journal of Biotechnology, 12(1): 1-9. 